\title{
The experience of mobile teledermatology during the COVID-19 pandemic in Nepal: A feasible alternative even in the developing world
}

\section{Suchana Marahatta}

\author{
Department of Dermatology and Venereology, B. P. Koirala Institute of Health Sciences, Ghopa Camp, Dharan-18, Sunsari, \\ Nepal
}

Corresponding author: Suchana Marahatta, MD, E-mail: suchanamarahatta@yahoo.com

Sir,

Because of the COVID-19 pandemic, our lives have become devastated and affected like never before. It has truly challenged the entire medical world. We, healthcare providers, are looking for the best ways of providing patient care in our respective fields. Although the first COVID-19 case in Nepal was confirmed on January 23 , cases have been rising rapidly for the last two months, once national lockdown ended on July 21. To date (i.e., October 6, 2020), there have been 89,263 confirmed cases and 554 deaths [1]. Although the lockdown has been eased in a phase-wise way, public mobility is still restricted only to urgent cases to combat the infection. At the same time, some people might be making unnecessary health visits due to the lack of a proper referral and triage system in our country. Likewise, a specialist visit is especially difficult because of the varying geographical landscape and centralization of the healthcare system [2]. For this reason, teledermatology might be a promising platform for triaging dermatology patients at a distance without face-to-face consultations. The skin being a visible organ, we have the potential to diagnose many cases with a medical history and a detailed visual inspection of lesions. Hence, by the use of teledermatology, we can easily segregate our patients with minimum patient mobilization using the store-and-forward technique, even in a resourcepoor setup. Dermatology being a visual discipline, we are very much privileged to practice teledermatology.
Mobile teledermatology-the use of smartphone teleconsultation applications-is another rapidly growing field [3]. As smartphones are becoming cheaper, more user-friendly, and more easily available, it might be a good alternative for teleconsultation even in underdeveloped nations. There have been specific guidelines for using mobile devices in dermatology practice as well [4].

Targeting this pandemic, I have been practicing free mobile teleconsultation since May 17, 2020, different social media. A total of 411 patients have contacted me for skin problems through the following social platforms: Facebook (386; 93.91\%) [5], WhatsApp (22; 5.35\%), and Viber $(3 ; 0.74 \%)$. However, the required details could be gathered from only 350 patients. The mean age was $35.05 \pm 16.0$ years, through with a minimum of 6 months and a maximum of 88 years). Females (51.1\%) predominated males. Almost half $(47.4 \%)$ were from semiurban areas, followed by $23.1 \%$ from rural areas. Some people $(10.3 \%)$ even contacted from abroad. Dermatitis and eczema were the most common (22.6\%) issues (Table 1). Several people (5.14\%) also contacted for genital issues without hesitating to share clinical photographs. The majority of people (78.6\%) contacted for their own issues, whereas several health workers (3.1\%) contacted for secondary teleconsultation for their patients. Establishing and maintaining a dialog with mobile teledermatology was particularly easy both for the patient and the dermatologist (Fig. 1). From the shared photographs and information, diagnosis and advice were possible in $90.9 \%$ of cases, thus obviating

\footnotetext{
How to cite this article: Marahatta S. The experience of mobile teledermatology during COVID-19 pandemic in Nepal: A feasible alternative even in the developing world. Our Dermatol Online. 2021;12(2):204-205.

Submission: 07.10.2020; Acceptance: 10.12.2020

DOI: 10.7241/ourd.20212.29
} 


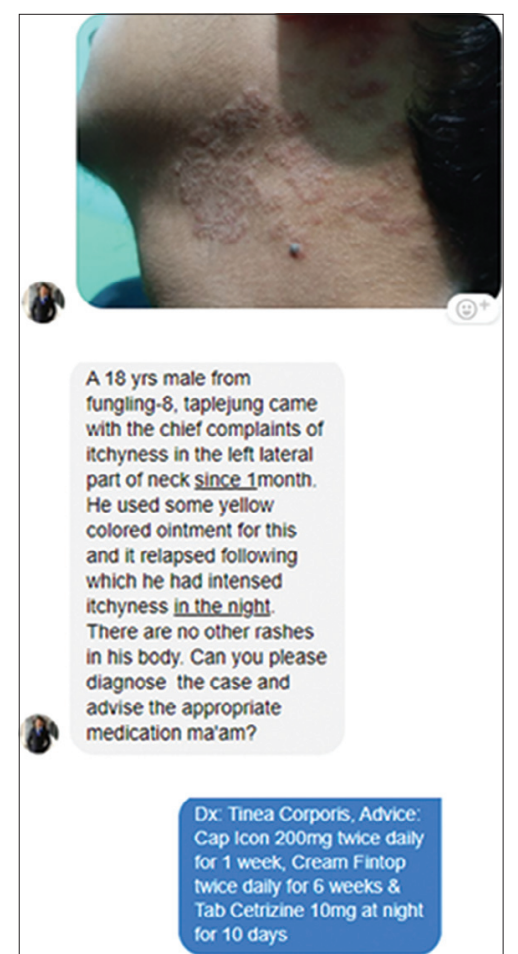

Figure 1: A dialogue during a mobile teledermatology consultation.

immediate specialist visits. For the rest (9.1\%), however, a diagnosis could not be established on such a platform.

From this small experience, we see huge possibilities of mobile teledermatology, even in developing countries, as it may significantly reduce the need for unnecessary hospital visits and mobilization of many dermatology patients during the pandemic, even in the future. Hence, we strongly agree with some proposed models of teledermatology [6]. An expert committee can prepare a common sustainable protocol of utilizing teledermatology to its fullest throughout the world during this crisis as well as in the days to come.
Table 1: The clinicodemographic profiles of the patients

\begin{tabular}{llcc}
\hline Characteristic & Category & Number & Percentage \\
\hline Gender & Male & 171 & 48.9 \\
Residence & Female & 179 & 51.1 \\
& Urban & 67 & 19.1 \\
& Semiurban & 166 & 47.4 \\
& Rural & 81 & 23.1 \\
& Abroad & 36 & 10.3 \\
Contacted by & Self & 275 & 78.6 \\
& Family member or friend & 64 & 18.3 \\
& Health worker & 11 & 3.1 \\
Diagnosis & Fungal infection & 48 & 13.7 \\
& Bacterial infection & 11 & 3.1 \\
& Viral infection & 14 & 4.0 \\
& Dermatitis and eczema & 79 & 22.6 \\
& Acne and acne scars & 60 & 17.1 \\
& Pigmentary problems & 65 & 18.6 \\
& Nevus, cyst, growth & 16 & 4.6 \\
& Urticaria & 18 & 5.1 \\
& Alopecia & 9 & 2.6 \\
& Others & 9 & 2.6 \\
& Diagnosis impossible & 32 & 9.1 \\
\hline
\end{tabular}

\section{REFERENCES}

1. WHO. Daily COVID-19 report. https://covid19.who.int/region/ searo/country/np. Published 2020 (search date 6th October 2020).

2. Shrestha S, Jha A. Teledermatology consulting centre: Which rural area is suitable? Nepal J Dermatol Venereol Leprol. 2009;8:10-2.

3. Jakhar D, Kaul S, Kaur I. WhatsApp messenger as a teledermatology tool during coronavirus disease (COVID-19): from bedside to phone-side. Clin Exp Dermatol. 2020;45:739-40.

4. British Association of Dermatologists. UK Guidance on the use of mobile photographic devices in dermatology. 2017. http://bit. ly/VayyN2.

5. Marahatta S. Facebook page. https://www.facebook.com/ dermacorner/. Published 2020.

6. Price KN, Thiede R, Shi VY, Curiel-Lewandrowski C. Strategic dermatology clinical operations during the coronavirus disease 2019 (COVID-19) pandemic. J Am Acad Dermatol. 2020;82:e207-9.

Copyright by Suchana Marahatta. This is an open-access article distributed under the terms of the Creative Commons Attribution License, which permits unrestricted use, distribution, and reproduction in any medium, provided the original author and source are credited.

Source of Support: Nil, Conflict of Interest: None declared. 